\title{
Physical activity and depression in older adults in times of the COVID-19 pandemic
}

\author{
Authors' Contribution: \\ A Study Design \\ B Data Collection \\ C Statistical Analysis \\ D Data Interpretation \\ E Manuscript Preparation \\ F Literature Search \\ G Funds Collection
}

\author{
Inci Kesilmiş̧ ${ }^{\text {ACDEFG }}$, Gülten Geçitli ${ }^{2}$ ABEF, Seda Kavak ${ }^{2}$ ABEF, Süleyman Kostal ${ }^{2}$ ABEF, \\ Mehmet Melih Kesilmiș ${ }^{3 \text { ACFG }}$ \\ ${ }^{1}$ Department of Physical Education and Sports, Osmaniye Korkut Ata University, \\ Osmaniye, Turkey \\ ${ }^{2}$ Undergraduate Student, Department of Physical Education and Sports, Osmaniye \\ Korkut Ata University,Osmaniye, Turkey \\ ${ }^{3}$ Master of Science, Hüseyin Özer Merzeci Middle School, Toroslar, Mersin, Turkey
}

abstract

Background: During the COVID-19 pandemic that affected the whole world, individuals aged 65 and over were in the group of "leaving home restriction" for a long time. Evaluation of physical activity and depression variables gains importance in the older adults who are physically exposed to inactivity.

Material and methods:

The research was conducted on 97 male and 78 female participants aged 65 and over with the "nonprobabilistic sampling methods with convenience sampling" method. The Physical Activity Scale for Elderly (PASE), Geriatric Depression Scale (GDS) and Katz Activities of Daily Living Scale were used as data collection tools.

Results: The difference between physical activity and geriatric depression by gender is statistically insignificant $(p>0.05)$. The difference between youngest-old and oldest-old age group according to the level of physical activity is statistically significant $(p<0.05)$ and this difference is in favor of the youngest-old group. A low-level significant correlation was observed between geriatric depression and the Physical Activity Level $(r=-0.150, p=0.047)$.

Conclusions: In the light of the findings obtained from the study, a decrease in depression is observed with an increase in physical activity in the older adults. It is recommended to develop strategies to support physical activity for the older adults in isolation.

Key words: coronavirus, PASE, mental health, youngest-old, middle-old, oldest-old.

\section{article details}

Article statistics: Word count: 4,250; Tables: 7; Figures: 0; References: 61

Received: February 2021; Accepted: October 2021; Published: December 2021

Full-text PDF: http://www.balticsportscience.com

Copyright @ Gdansk University of Physical Education and Sport, Poland

Indexation: Celdes, Clarivate Analytics Emerging Sources Citation Index (ESCI), CNKI Scholar (China National Knowledge Infrastructure), CNPIEC, DOAJ, EBSCO - Central \& Eastern European Academic Source, EBSCO - SPORTDiscus, EBSCO Discovery Service, Google Scholar, Index Copernicus, J-Gate, Naviga (Softweco, Primo Central (ExLibris), ProQuest - Family Health, ProQuest - Health \& Medical Complete, ProQuest - Illustrata: Health Sciences, ProQuest Nursing \& Allied Health Source, Summon (Serials Solutions/ProQuest, TDOne (TDNet), Ulrich's Periodicals Directory/ ulrichsweb, WorldCat (OCLC)

Funding: This research received no specific grant from any funding agency in the public, commercial, or not-for-profit sectors. This study presented as an oral presentation at "4th International Mediterranean Symposium on 22-24 October 2020, Mersin Turkey"

Conflict of interests: Authors have declared that no competing interest exists.

Corresponding author: İnci KESiLMiş, Department of Physical Education and Sports, Osmaniye Korkut Ata University, Osmaniye, Turkey; e-mail: incikesilmis@gmail.com; +90 (328) 8271000 / 6004

Open Access License: This is an open access article distributed under the terms of the Creative Commons Attribution-Non-Commercial-NoDerivatives 4.0 International (https://creativecommons.org/licenses/by-nc-nd/4.0/), which permits use, distribution, and reproduction in any medium, provided the original work is properly cited, the use is non-commercial and is otherwise in compliance with the license. 


\section{INTRODUCTION}

The world has faced a threat from the 2019 Coronavirus disease that caused globally problems [1]. Older adults are among the most severely affected by negative consequences of the coronavirus disease in the general population [2]. With aging, psychological, social and physiological sensitivities occur. Due to the weakening of the immune system, the risks of infection increase with aging. Additionally, older people have multiple comorbidities and are more likely to be infected during a pandemic than the young population [3]. In Turkey, the first coronavirus case was reported on March 11, 2020. With the rapid increase in the number of cases, curfews have been imposed on individuals over the age of 65. Accordingly, older adult individuals aged 65 and over were exposed to physical inactivity. It is pointed out that being in social isolation is a "serious public health problem" for the older adult population due to their bio-psycho-social weaknesses [4]. In Turkey, although curfew and social isolation of the older adults is an important strategy in preventing coronavirus disease, it may cause depression, as well as prepare the ground for the emergence of different health problems caused by physical inactivity. Physical inactivity, along with non-contagious diseases such as high blood pressure, high blood sugar and obesity, may globally be a cause of deaths as a major risk factor that threatens the general health of the society [5]. Participation in regular physical activity is a healthy habit that is extremely effective in increasing the quality of life and reducing the prevalence of chronic diseases in the older adult population [6]. Regular physical activity in older adults may delay the negative changes connected with ageing. It is also of great importance for maintaining health and increasing work capacity [7]. Physical activity has a critical role in preventing illnesses in the older adults, increasing the level of independence in daily life activities and contributing to mental well-being. In addition to the positive effects of physical activity on physiological changes and various chronic diseases, it has been reported to have significant effects on general mental health and well-being [8-10]. Mental health and well-being enable people to see life as meaningful and creative as the basis of the quality of life. At the same time, mental health is an indispensable element of social cohesion, productivity, and peace and stability in the living environment and contributes to the social capital and economic development in societies [11]. People who are mentally unwell appear to have a physically sedentary lifestyle compared to those who are mentally better [12,13]. Some factors seem to determine how mental illnesses begin, their incidence and the course of the illness. These are social and economic factors, demographic factors, such as gender and age, serious threats, such as conflict and disasters. In the studies examining the prevalence, causality and course of mental illness, gender differences are increasingly stressed. Mental disturbances are also related to the social environment of the individual. Various social factors affect the onset, course, and outcome of mental disorders [14]. In addition to physical activity being negatively affected during the quarantine, mental health is also affected. Studies reporting that the mental health of the general population was negatively affected in the pandemics (SARS) before COVID-19, explaining the high risk of depression, where physical activity and healthy living strategies are recommended for reducing post-traumatic stress [15, 16] are available [17]. There are also studies reporting that loneliness is an important health problem among older adults [18]. Social relationships, which are a part of people's quality of life and social adaptation, have protective effects on morbidity and mortality outcomes $[19,20]$. For this reason, in addition to the existing risks of being physically inactive, this risk seems to have increased even more for the older adults group, who may be mentally affected by social isolation. However, little is known about the impact of the new COVID-19 pandemic on physical activity and mental health in older adults. Callow et al. [21] concluded that participating in even low-level physical activity during the COVID-19 pandemic can help mitigate some of the negative mental health effects of older adults.

There are review studies for COVID-19 in which it is strongly recommended that the elderly receive regular exercise training at home to support the functioning of the immune system, 
where mental health is negatively affected in the older adults [22] during social distancing [23]. However, the effects of COVID-19 quarantine on physical activity and mental health in the older adults have not yet been widely studied. From this point of view, the purpose of this study is to evaluate the physical activity levels and mental health of individuals over 65 years of age in the period of COVID-19, depending on gender and age groups.

\section{METHODS}

\section{PARTICIPANTS AND PROCEDURE}

The research was conducted with the "non-probabilistic sampling methods with convenience sampling" method on older adult individuals aged 65 and over who stayed at home for a long time due to the COVID-19 pandemic (all data were collected in June and July 2020). As recommended by the World Health Organization (WHO), periods of older adulthood are as follows: 65-74 years old are grouped as "youngest-old", 75-84 years old as "middleold" and 85 years and above as "oldest-old". This study is a cross-sectional study. Before the research, the Ethical Approval Certificate (19957-2020-26-6) was obtained from the Scientific Research and Publication Ethics Committee and then data collection started. Informed consent was provided by all participants. In order to conduct the survey, all participants were informed about the social distance rules, and the researchers applied the questionnaires in the open area while wearing masks. The inclusion criteria for the study were being at the age of 65 and over and following the leaving home restriction. The exclusion criteria were determined as going to work, being bedridden patient or having physical disabilities that would prevent one from doing physical activity. In total, 104 male and 85 female participants were reached, but after calculating the $\mathrm{Z}$ values, the extreme values were excluded from the study, and the data of 97 male and 78 female participants (175 in total) were used for statistical analysis. The data were analyzed in terms of extreme values using the standard Z score transformation with the help of SPSS-20. Participants whose $\mathrm{Z}$ score was between -3 and +3 remained in the dataset, and participants whose $Z$ score was less than -3 or greater than +3 were defined as extreme value and they were excluded from the study [24]. The participants' body height and body mass were measured using a height-linked SECA digital weighing machine.

Table 1. Descriptive statistics according to gender and age groups

\begin{tabular}{|c|c|c|c|c|c|c|c|}
\hline Age Groups & Gender & Variables & $\mathrm{N}$ & Minimum & Maximum & Mean & $\begin{array}{c}\text { Std. } \\
\text { Deviation }\end{array}$ \\
\hline \multirow{4}{*}{$\begin{array}{l}\text { Youngest- } \\
\text { old }\end{array}$} & \multirow{2}{*}{ Male } & Body Height (cm) & 68 & 160.00 & 187.00 & 172.59 & 5.97 \\
\hline & & Body Weight (kg) & 68 & 55.00 & 110.00 & 78.97 & 11.16 \\
\hline & \multirow{2}{*}{ Female } & Body Height (cm) & 67 & 150.00 & 173.00 & 160.58 & 5.45 \\
\hline & & Body Weight (kg) & 67 & 50.00 & 110.00 & 72.64 & 9.84 \\
\hline \multirow{4}{*}{ Middle-old } & \multirow{2}{*}{ Male } & Body Height (cm) & 25 & 150.00 & 183.00 & 171.76 & 8.14 \\
\hline & & Body Weight (kg) & 25 & 44.00 & 95.00 & 77.88 & 11.27 \\
\hline & \multirow{2}{*}{ Female } & Body Height $(\mathrm{cm})$ & 9 & 150.00 & 170.00 & 158.33 & 6.86 \\
\hline & & Body Weight (kg) & 9 & 50.00 & 110.00 & 73.00 & 16.80 \\
\hline \multirow{4}{*}{ Oldest-old } & \multirow{2}{*}{ Male } & Body Height (cm) & 4 & 175.00 & 185.00 & 180.50 & 4.20 \\
\hline & & Body Weight (kg) & 4 & 68.00 & 94.00 & 82.50 & 11.82 \\
\hline & \multirow{2}{*}{ Female } & Body Height (cm) & 2 & 165.00 & 168.00 & 166.50 & 2.12 \\
\hline & & Body Weight (kg) & 2 & 70.00 & 70.00 & 70.00 & 0.00 \\
\hline
\end{tabular}




\section{PHYSICAL ACTIVITY SCALE FOR THE ELDERLY (PASE)}

The scale is a short, valid, and reliable method used in epidemiological studies conducted with older adults aged 65 and over. PASE consists of a combination of multiple scores that include leisure activities, housework and busy activities and is a systematically developed scale with proven reliability and validity in 277 geriatric patients over the age of 73 [25]. Validity and reliability of the Turkish version was performed by Ayvat et al. [26]. PASE measures the level of physical activity of individuals aged 65 and over. It is a self-scoring scale based on household chores and leisure activities performed within a week. Scoring is made with the data obtained from an electronic physical activity monitor, activity diaries or the activity level that the person evaluates himself, in the older adults who live in the community and do not have any institutional relationship.

In the Turkish validity and reliability study of the scale, the Cronbach $\alpha$ coefficient for the first evaluation was reported as 0.714 . The intraclass correlation coefficient for test-retest test reliability is 0.995, and the 95\% confidence interval is 0.993-0.997.

\section{GERIATRIC DEPRESSION SCALE (GDS)}

Yesevage \& Sheikh [27] first developed GDS and reported it to be valid and reliable. It is a self-report scale prepared to measure depression, especially in the older adult population. The scale is composed of 30 questions, as well as symptoms that may occur for reasons other than depression for the older adult population, and can be answered as "yes" or "no", which older adults can easily mark. The validity of the scale of the short form in Turkey and reliability study was conducted in 2018 by Durmaz et al. [28] The Cronbach alpha coefficient for the scale was 0.920 .

\section{KATZ DAILY ACTIVITIES SCALE}

Katz's Daily Living Activities Questionnaire consists of 7 questions including information about bathing, dressing, toilet, movement, excretion, and feeding activities. Those who get 6 full points from the scale are categorized as "fully independent", those who score 4 as "moderately dependent", and those who score 2 and below as "severely dependent". The scale was developed by Shelkey and Wallace [29]. The Turkish validity and reliability study was conducted by Pehlivanoğlu et al. [30], and the scale was reported to be valid and reliable (the Cronbach Alpha coefficient was 0.83).

\section{STATISTICAL ANALYSIS}

Z-scores were calculated for all data, and participants with extreme values were excluded from the study ( 7 males, 7 females). In order to determine the normality of the distribution, the Shapiro-Wilk test was performed, Skewness-Kurtosis values were calculated, and it was tested whether the variance coefficient was less than 0.30 . Since the distribution was normal, Cohen's d and effect size $r$ were calculated in addition to the independent sample t-Test in comparisons based on gender. One-way ANOVA was used for comparisons based on age groups, and LSD values from the post-hoc tests were used. Pearson's correlation coefficient was used to determine the correlation between physical activity and geriatric depression. ANCOVA analysis was performed to determine which variable had a stronger effect on the severity of geriatric depression. ANCOVA assumptions were checked. The distribution of the scores of the dependent variable for each of the groups was normal. The homogeneity of variance and the equality of the regression coefficients within the groups were examined. Since more than one covariate was used, there should not be a strong correlation between these covariates. The correlation coefficient between covariates was found to be 0.23 . The assumption of a linear relationship between the covariates and the dependent variable was met. The strength and direction of the correlation between the covariate and the dependent variable should be similar in each group. In this study, the regression was found to be homogeneous in the groups. The significance level was taken as $\mathrm{p}<0.05$ for all analyses. 


\section{RESULTS}

The mean and standard deviation values of the participants' physical activity and geriatric depression scores were categorized according to age groups and gender (Table 2). When Katz daily life activities of all participants in the study were evaluated, it was determined that all participants were in the "fully independent" group.

Table 2. Descriptive statistics according to age groups and gender

\begin{tabular}{|c|c|c|c|c|c|c|c|}
\hline Age Groups & Gender & Variables & $\mathrm{N}$ & Minimum & Maximum & Mean & $\begin{array}{c}\text { Std. } \\
\text { Deviation }\end{array}$ \\
\hline \multirow{4}{*}{$\begin{array}{l}\text { Youngest- } \\
\text { old }\end{array}$} & \multirow{2}{*}{ Male } & PASE & 68 & 0.00 & 214.00 & 96.62 & 53.00 \\
\hline & & GD & 68 & 0.00 & 15.00 & 5.90 & 4.07 \\
\hline & \multirow{2}{*}{ Female } & PASE & 67 & 0.00 & 204.00 & 78.30 & 45.29 \\
\hline & & GD & 67 & 1.00 & 15.00 & 6.21 & 3.52 \\
\hline \multirow{4}{*}{ Middle-old } & \multirow{2}{*}{ Male } & PASE & 25 & 0.00 & 191.00 & 73.88 & 52.22 \\
\hline & & GD & 25 & 0.00 & 14.00 & 5.24 & 4.40 \\
\hline & \multirow{2}{*}{ Female } & PASE & 9 & 14.00 & 136.00 & 59.11 & 34.38 \\
\hline & & GD & 9 & 0.00 & 13.00 & 6.11 & 3.89 \\
\hline \multirow{4}{*}{ Oldest-old } & \multirow{2}{*}{ Male } & PASE & 4 & 6.00 & 101.00 & 43.00 & 44.94 \\
\hline & & GD & 4 & 1.00 & 9.00 & 6.25 & 3.59 \\
\hline & \multirow{2}{*}{ Female } & PASE & 2 & 6.00 & 33.00 & 19.50 & 19.09 \\
\hline & & GD & 2 & 6.00 & 8.00 & 7.00 & 1.41 \\
\hline
\end{tabular}

Note. PASE = Physical Activity Scale for the Older Adults Scale Scores, GD= Geriatric Depression Scores

Table 3. Independent samples t-test, Cohen's d and effect size r results for physical activity and geriatric depression according to gender

\begin{tabular}{|c|c|c|c|c|c|c|c|c|c|c|}
\hline 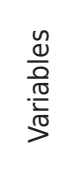 & 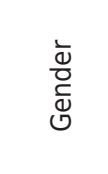 & $z$ & 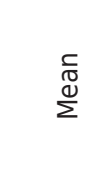 & 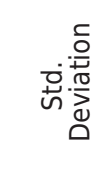 & 总 & + & $\frac{4}{0}$ & & $\begin{array}{l}0 \\
-n \\
-\frac{1}{d} \\
\frac{1}{0} \\
0\end{array}$ & 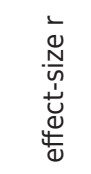 \\
\hline \multirow{2}{*}{ PASE } & Male & 97 & 88.55 & 53.79 & 5.46 & \multirow{2}{*}{1.838} & \multirow{2}{*}{173} & \multirow{2}{*}{0.068} & \multirow{2}{*}{0.282} & \multirow{2}{*}{0.140} \\
\hline & Female & 78 & 74.58 & 44.77 & 5.07 & & & & & \\
\hline \multirow{2}{*}{ GD } & Male & 97 & 5.74 & 4.11 & 0.42 & \multirow{2}{*}{-0.827} & \multirow{2}{*}{172.435} & \multirow{2}{*}{0.409} & \multirow{2}{*}{-0.124} & \multirow{2}{*}{-0.062} \\
\hline & Female & 78 & 6.22 & 3.50 & 0.40 & & & & & \\
\hline
\end{tabular}

Note: PASE=Physical Activity Scale for the Older Adults Scale Scores, GD=Geriatric Depression Scores

The difference between physical activity and geriatric depression by gender is statistically insignificant $(\mathrm{p}>0.05)$.

Table 4. One-way ANOVA results for PASE and GD according to age groups

\begin{tabular}{|c|c|c|c|c|c|c|}
\hline & & $\begin{array}{l}\text { Sum of } \\
\text { Squares }\end{array}$ & $d f$ & Mean Square & $\mathrm{F}$ & Sig. \\
\hline & Between Groups & 22184.62 & 2 & 11092.31 & & \\
\hline \multirow[t]{3}{*}{ PASE } & Within Groups & 418397.46 & 172 & 2432.54 & 4.560 & $0.012 *$ \\
\hline & Total & 440582.08 & 174 & & & \\
\hline & Between Groups & 11.03 & 2 & 5.51 & & \\
\hline \multirow[t]{2}{*}{ GD } & Within Groups & 2562.61 & 172 & 14.90 & 0.370 & 0.691 \\
\hline & Total & 2573.63 & 174 & & & \\
\hline
\end{tabular}

Note: PASE=Physical Activity Scale for the Older Adults Scale Scores, GD= Geriatric Depression Scores, $* p<0.05$ 
Table 5. One-way ANOVA LSD results for physical activity and geriatric depression according to age groups

\begin{tabular}{|c|c|c|c|c|c|c|c|}
\hline \multirow[b]{2}{*}{ LSD } & & & \multirow{2}{*}{$\begin{array}{c}\text { Mean } \\
\text { Difference } \\
(\mathrm{I}-\mathrm{J})\end{array}$} & \multirow[b]{2}{*}{ Std. Error } & \multirow[b]{2}{*}{ Sig. } & \multicolumn{2}{|c|}{ 95\% Confidence Interval } \\
\hline & & & & & & $\begin{array}{l}\text { Lower } \\
\text { Bound }\end{array}$ & $\begin{array}{l}\text { Upper } \\
\text { Bound }\end{array}$ \\
\hline \multirow{6}{*}{ 岕 } & \multirow{2}{*}{ Youngest-old } & Middle-old & 17.555 & 9.464 & 0.065 & -1.125 & 36.236 \\
\hline & & Oldest-old & $52.359 *$ & 20.578 & 0.012 & 11.742 & 92.977 \\
\hline & \multirow{2}{*}{ Middle-old } & Youngest-old & -17.555 & 9.464 & 0.065 & -36.236 & 1.125 \\
\hline & & Oldest-old & 34.804 & 21.840 & 0.113 & -8.304 & 77.912 \\
\hline & \multirow{2}{*}{ Oldest-old } & Youngest-old & $-52.359 *$ & 20.578 & 0.012 & -92.977 & -11.742 \\
\hline & & Middle-old & -34.804 & 21.840 & 0.113 & -77.912 & 8.304 \\
\hline \multirow{6}{*}{ ㅇ } & \multirow{2}{*}{ Youngest-old } & Middle-old & 0.581 & 0.741 & 0.434 & -0.881 & 2.043 \\
\hline & & Oldest-old & -0.448 & 1.610 & 0.781 & -3.627 & 2.731 \\
\hline & \multirow{2}{*}{ Middle-old } & Youngest-old & -0.581 & 0.741 & 0.434 & -2.043 & 0.881 \\
\hline & & Oldest-old & -1.029 & 1.709 & 0.548 & -4.403 & 2.344 \\
\hline & \multirow{2}{*}{ Oldest-old } & Youngest-old & 0.448 & 1.610 & 0.781 & -2.731 & 3.627 \\
\hline & & Middle-old & 1.029 & 1.709 & 0.548 & -2.344 & 4.403 \\
\hline
\end{tabular}

The difference between youngest old group and oldest-old group according to PASE physical activity level is statistically significant $(\mathrm{p}<0.05)$, and this difference is in favor of the youngest-old group. Geriatric depression does not differ according to age groups. According to the Pearson correlation coefficient results, a low-level significant correlation was observed between geriatric depression and the physical activity level $(r=-0.150, p=0.047)$.

The mean score of the GD corrected according to the age and PASE of the participants were given in Table 6. Accordingly, the mean score of depression was calculated as 5.74 for females and 6.22 for males. Considering the mean scores, it can be concluded that the depression score of the male participants was higher than that of the females. The adjusted mean scores for the depression variable were 5.817 for females and 6.029 for males.

Table 6. Descriptive statistics of participants' depression scores by gender

\begin{tabular}{cccc} 
Gender & N & Mean & Corrected mean \\
\hline Female & 97 & 5.74 & 5.82 \\
Male & 78 & 6.22 & 6.03 \\
\hline
\end{tabular}

If the groups GD scores were placed in an order from high to low according to their corrected depression mean scores, it can be stated that the depression levels of males were higher than of females. The ANCOVA results regarding whether the observed difference between the corrected depression mean scores of the groups was significant are given in Table 7.

Table 7. ANCOVA results of depression scores adjusted for age and physical activity scale by gender

\begin{tabular}{cccccc} 
Source & Sum of Squares & df & Mean Square & F & Sig. \\
\hline PASE & 61.812 & 1 & 61.812 & 4.227 & 0.041 \\
Age (year) & 10.634 & 1 & 10.634 & 0.727 & 0.395 \\
Gender & 1.525 & 1 & 1.525 & 0.104 & 0.747 \\
Error & 2500.629 & 171 & 14.624 & & \\
Total & 8778.000 & 175 & & & \\
Corrected Total & 2573.634 & 174 & & & \\
\hline
\end{tabular}

Note R Squared $=0.028$ (Adjusted R Squared $=0.011$ ) 
According to ANCOVA results, no significant difference was found between the mean depression scores of females and males adjusted for age and physical activity scale $F(1.171)=0.104, p>0.05$. In other words, the depression levels of the participants were not related to gender.

\section{DISCUSSION}

In this study, which aims to determine physical activity and depression in the older adults who are exposed to compulsory social isolation because they are in the risk group during the COVID-19 pandemic, it was found that depression decreases as the level of physical activity increases. There is no difference based on gender, and the difference depending on age groups was observed only between youngest-old and oldest-old (Table 3). In the prepandemic literature, there are studies that conclude that female participants have higher geriatric depression scores compared to males [31, 32]. In a study conducted during the COVID-19 pandemic, similarly to our research, no gender-related difference was observed in the mental health variable [2].

In studies on physical activity, Soyuer et al. [33] reported that, depending on gender, the level of physical activity in adults 65 years old and older differs in favor of male participants. However, these findings are in conflict with our research. If we evaluate the PASE mean scores in the studies conducted before the pandemic, Covotta et al. [34] reported the PASE mean value as $159 \pm 77.88$, Ismail et al. [35] as 94.96, and Vaughan and Miller [40] as 131.3. In our study, while mean values according to gender are $88.55 \pm 53.79$ for males and $74.58 \pm 44.77$ for females (Table 2), it is striking that the activity levels of older adults during the COVID-19 are much lower than the current literature. While it is not possible to directly compare the pre-COVID-19 results with the results in the present article, based on the survey, it can be shown that respondents do less physical activity, which could be a result of the pandemic. At the same time, the PASE mean score of $102.5 \pm 63.8$ was reported in a study conducted during the COVID-19 pandemic [21]. Castañeda-Babarro [36] observed that physical activity significantly decreased during social restriction due to pandemic. In addition, López-Sánchez et al [37] showed a reduction in excessive and vigorous physical activity in males and females with chronic conditions during the COVID-19 quarantine. In our study, the following comment can be made regarding female and male participants, in contrast to the pre-pandemic literature, but in line with the literature during the pandemic period: due to the long stay of both groups at home during the COVID-19 pandemic, the reason why physical activity and depression levels do not differ can be interpreted as male participants may have increased depression level and decreased physical activity level.

According to PASE physical activity level, the difference between youngest-old and oldest-old age is statistically significant ( $\mathrm{p}<0.05$ ), and this difference is in favor of the latter adult group (Table 4). Milanovic et al. [38] hypothesized that there would be an age-related decrease in the level of physical activity in 60-69 and 70-80-year-old participants, and it was reported that physical activity decreases with the advancement of age. Our research findings are consistent with many studies in the literature [34, 39, 40]. New studies are needed for comparative literature on age-related physical activity changes during the COVID period. According to our research findings, geriatric depression does not differ according to age groups ( $p>0.05)$ (Table 4). There are studies that have obtained similar results [31, 41]. However, various studies have proven that the severity of depressive symptoms significantly increases in males in different age categories (e.g., 32-45, 46-55, 56-65, 66-79 years old) [42].

In addition, in the study conducted by Zincir et al. [43] to examine the correlation between the quality of life of older adult people living in nursing homes and depression and the factors affecting it, they reported that geriatric depression did not significantly differ according to age groups $(p=0.601)$. 
According to the Pearson correlation coefficient results, a low-level significant correlation was observed between geriatric depression and physical activity level ( $r=-0.150, p=0.047)$. Functional aging is characterized by performance decrease abilities related to coordination, flexibility, strength and endurance [44]. After the age of 30, maximum aerobic dynamic performance capacity decreases by an average of $8 \%$ per decade. Skeletal muscle strength decreases especially after the age of 50-60. The main reason is the reduction in the number of motor units and muscle fibers [45]. In the study in which Yücel and Kayshan [46] investigated the effect of multi-purpose activity training given to older adults living in nursing homes on depression, a significant decrease in depression was found in both groups after activity training $(\mathrm{p}<0.05)$. They reported that providing older adults with a variety of activities and creating desires and opportunities for participating in regular and continuous activities should be promoted to reduce their depression. Lök and Bademli [47], in their study with 286 participants aged 65 and over, found that there was a high-level negative correlation between physical activity and depression. Dankel et al. [48] reported an increase in depressive symptoms in inactive individuals. In the systematic review by Mammen and Faulkner [49], it was emphasized that increasing physical activity is a valuable strategy in improving mental health and reducing the risk of developing depression. Similar to our study, Cengiz \& Delen [50] reported that as the level of physical activity increases, depression levels decrease in individuals between the ages of 60-69. While exercise and other types of physical activity provide numerous physiological and psychosocial benefits to older individuals, it is stated that there is a strong link between inactivity and chronic diseases in the 20th century [51]. Lök and Bademli [47] stated that after the ten-week "Physical Activity Program", the depressive symptoms of the older adults decreased, and their quality of life improved.

Physical inactivity is defined as the level of physical activity "lower than necessary" in order to maintain good health (physical fitness). The World Health Organization reports physical inactivity as the fourth biggest risk factor for global mortality and the biggest public health problem of the 21st century [52]. The correlation between high or low physical activity and human health is becoming more and more important worldwide. In addition to the fact that insufficient physical activity is the source of health problems, the contribution of physical activity to the prevention or improvement of many health problems has been revealed in many studies [53,54]. In conclusion, it can be said that there is a negative and significant correlation between physical activity and geriatric depression, and according to these results, it can be said that individuals pay more attention to physical activity, which is one of the three basic dimensions of health-related quality of life, in their daily lives. When reviewing a post-pandemic study, the results of the research of Callow et al. [21], examining the correlation between physical activity level and mental health during the COVID-19 term, are similar to our study. Physical activity is an important part of healthy aging in terms of preventing or slowing the progression of several chronic diseases. A sedentary lifestyle and lack of physical activity result in significantly accelerated aging rates for people of all age groups, reflecting the general trend of deterioration in quality of life and health [7]. The World Health Organization estimates that every dollar spent on physical activity promotion will save $\$ 3.2$ in the costs of providing medical care for the health system. In addition to the pandemic such as COVID-19, it is especially important to protect the older adults from diseases, including chronic diseases, depression. Because old age is a period that can affect all systems of the human body [25]. At the same time, considering the age-specific hormonal changes of the research group, it is suggested that the symptoms of depression in male participants may be caused by the deficiency in the concentration of neurosteroids [55-57]. There is also evidence of a strong association between hypogonadism and depression in postmenopausal females [58, 59].

The strength of this study, which examines the state of inactivity and depression that will pose a great risk for older adults during the pandemic process, is that the data are collected 
face-to-face, so that there is no uncontrolled participation of people outside the age group while collecting data online. In addition, proving that the participants are fully independent through the Katz questionnaire is one of the strengths of the research. Since this study is cross-sectional, it remains weak in determining causation. Given the long-term social isolation of the older adults during the current pandemic, these people are at higher risk for mental health problems associated with social isolation and health problems that may be caused by inactivity. For this reason, it is very important to identify safe and healthy ways in which older adults can protect their mental health and to develop and implement strategies. It is recommended to broadcast daily programs that can be easily applied by all older people, which can be done safely at home, and that contain movements that will positively contribute to physical activity, and to encourage activities with these programs.

\section{CONCLUSION}

According to the United Nations, there are 703 million people aged 65 and over worldwide as of 2019 , and these figures show that approximately $10 \%$ of the world's population is at high risk for COVID-19 [60]. It is still unclear when the pandemic will definitely end. Therefore, strategies are needed to reduce functional decline in older adults and provide mental affirmations related to physical activity to prevent inactivity. Just as seniors can do resistance / strength training at home [61], older adults need to help integrate simple and safe ways to stay physically active in a confined space. Programs that include activities that the older adults can do daily at home can be broadcast through easily accessible television programs, thus helping to reduce the symptoms of depression that may be caused by lack of social communication during the quarantine period.

\section{REFERENCES}

[1] World Health Organization. Coronavirus Disease (COVID-19) Pandemic. https://www.who.int/emergencies/diseases/ novel-coronavirus-2019 (accessed December 12, 2020).

[2] García-Fernández L, Romero-Ferreiro V, López-Roldán PD, Padilla S, Rodriguez-Jimenez R. Mental health in older adults Spanish people in times of COVID-19 outbreak. Am J Geriat Psychiatr. 2020;28(10):1040-1045. https://doi. org/10.1016/j.jagp.2020.06.027

[3] Banerjee D. The Impact of COVID-19 Pandemic on older adults mental health. Int J Geriatr Psychiatr. 2020;35:14661467. https://doi.org/10.1002/gps.5320

[4] Armitage R, Nellums LB. COVID-19 and the consequences of isolating the older adults. Lancet Public Health. 2020;5(5):e256. https://doi.org/10.1016/S2468-2667(20)30061X

[5] WHO The global burden of disease: 2004 update, World Health Organization, Geneva; 2008.

[6] Huang TT, Liu CB, Tsai YH, Chin YF, Wong CH. Physical fitness exercise versus cognitive behavior therapy on reducing the depressive symptoms among community-dwelling older adults: A randomized controlled trial. Int J Nurs Stud. 2015;52(10):1542-1552. https://doi.org/10.1016/j.ijnurstu.2015.05.013

[7] Andrieieva O, Hakman A, Kashuba V, et al. Effects of physical activity on aging processes in older adults persons. J Phys Educ Sport. 2019;19(4):1308-1314. https://doi.org/10.7752/jpes.2019.s4190

[8] Chodzko-Zajko WJ, Proctor, DN, Fiatarone Singh MA, et al. Exercise and physical activity for older adults. J Am Coll Sport Med. 2009;41(7):1510-1530. https://doi.org/10.1249/MSS.0b013e3181a0c95c

[9] Mather AS, Rodriguez C, Guthrie MF, McHarg AM, Reid IC, McMurdo MET. Effects of exercise on depressive symptoms in older adults with poorly responsive depressive disorder: Randomized controlled trial. Br J Psychiatr. 2002;180:411-415. https://doi.org/10.1192/bjp.180.5.411

[10] Spirduso WW, Francis KL, MacRae PG. Health, exercise and cognitive function. Physical dimensions of aging. 2nd ed. Champaign, IL: Human Kinetics; 2005, 211-232.

[11] Mental Health Commission of NSW Physical health and mental wellbeing: Evidence guide. Sydney, Mental Health Commission of NSW C 2016 State of New South Wales.

[12] Daumit GL, Goldberg RW, Anthony C, et al. Physical activity patterns in adults with severe mental illness. J Nerv Ment Dise. 2005;193:641-646. https://doi.org/10.1097/01.nmd.0000180737.85895.60

[13] Schmitz N, Kruse J. Kugler J. The association between physical exercises and health-related quality of life in subjects with mental disorders: Results from a cross-sectional survey. Prevent Med. 2004;39(6):1200-1207. https://doi. org/10.1016/j.ypmed.2004.04.034

[14] WHO Mental Health: New Understanding, New Hope.

[15] Maunder R, Hunter J, Vincent L, et al. The immediate psychological and occupational impact of the 2003 SARS outbreak in a teaching hospital. Cmaj. 2003;168:1245-1251

[16] Maunder RG, Lancee WJ, Balderson KE, et al. Long-term psychological and occupational effects of providing hospital healthcare during SARS outbreak. Emerg Infect Dis. 2006;12:1924-1932. https://doi.org/10.3201/eid1212.060584 
[17] Yoon MK, Kim SY, Ko HS, Lee MS. System effectiveness of detection, brief intervention and refer to treatment for the people with post-traumatic emotional distress by MERS: A case report of community-based proactive intervention in South Korea. Int J Ment Health Syst. 2016;10(1):1-5. https://doi.org/10.1186/s13033-016-0083-5

[18] Gerst-Emerson K, Jayawardhana J. Loneliness as a public health issue: The impact of loneliness on health care utilization among older adults. Am J Publ Health. 2015;105(5):1013-1019. https://doi.org/10.2105/AJPH.2014.302427

[19] Seeman T. How do others get under our skin? Social relationships and health. In: Ryff CD, Singe BH, eds. Emotion, Social Relationships, and Health. New York, NY: Oxford University Press; 2001, 189-209.

[20] Steptoe A, Shankar A, Demakakos P, Wardle J. Social isolation, loneliness, and all-cause mortality in older men and women. Proceedings of the National Academy of Sciences of the USA. 2013;110(15):5797-5801. https://doi. org/10.1073/pnas.1219686110

[21] Callow DD, Arnold-Nedimala NA, Jordan LS, et al. The mental health benefits of physical activity in older adults survive the COVID-19 pandemic. Am J Geriatr Psychiatr. 2020;28(10):1046-1057. https://doi.org/10.1016/j.jagp.2020.06.024

[22] Sepulveda-Loyola W, Rodríguez-Sánchez I, Perez-Rodriguez P, et al. Impact of social isolation due to COVID-19 on health in older people: Mental and physical effects and recommendations. J Nutr Health Aging. 2020;1-10. https:// doi.org/10.1007/s12603-020-1469-2

[23] Abdelbasset WK. Stay home: role of physical exercise training in older adults individuals' ability to face the COVID-19 infection. J Immun Res. 2020;8375096. https://doi.org/10.1155/2020/8375096

[24] Schötz S, Frid J, Gustafsson L, Löfqvist A. Functional data analysis of tongue articulation in Gothenburg and Malmöhus Swedish/i, y, u. Proceedings of Fonetikk, 2013;69.

[25] Washburn RA, Smith KW, Jette AM, Janney CA The physical activity scale for the older adults (PASE): Development and evaluation. J Clin Epidemiol. 1993;46:153-62. https://doi.org/10.1016/0895-4356(93)90053-4

[26] Ayvat E, Kılınç M, Kırdı N. The Turkish version of the Physical Activity Scale for the older adults (PASE): Its cultura adaptation, validation, and reliability. Turk J Med Sci. 2017;47(3):908-915. https://doi.org/10.3906/sag-1605-7

[27] Yesavage JA, Sheikh JI. Geriatric Depression Scale (GDS) Recent evidence and development of a shorter. Clin Gerontol. 1986;5:165-73. https://doi.org/10.1300/J018v05n01 09

[28] Durmaz B, Soysal P, Ellidokuz H, Isik AT. Validity and reliability of geriatric depression scale-15 (short form) in Turkish older adults. Northern Clin Istanbul. 2018;5(3):216. https://doi.org/10.14744/nci.2017.85047

[29] Shelkey M, Wallace M. Katz Index of independence in activities of daily living. J Gerontol Nurs. 1999;25(3):8-9. https://doi.org/10.3928/0098-9134-19990301-05

[30] Pehlivanoğlu EFÖ, Özkan MU, Balcıoğlu H, Bilge U, Ünlüoğlu İ. Adjustment and Reliability of Katz Daily Life Activity Measures for Elderly in Turkish. Ankara Med J. 2018;18(2):219-223. https://doi.org/1017098/amj.435264

[31] Bingöl G, Demir A, Karabek R, Kepenek B, Yıldırım N, Kaytaz EG. Analysing the depression levels of the individuals more than 65 in terms of some variables. Med J Goztepe Training and Research Hospital. 2010;25(4):169-176. https://doi.org/10.5222/J.GOZTEPETRH.2010.169

[32] Dişçigil G, Gemalmaz A, Başak O, Gürel FS, Tekin N. Depression in geriatric age group in a primary care setting Turkish Journal of Geriatrics. 2005;8(3):129-133.

[33] Soyuer F, Şenol V, Elmalı F. physical activity, balance and mobility functions of 65 and over older people living at rest home. Van Med J. 2012;19(3):116-121.

[34] Covotta A, Gagliardi M, Berardi A, et al. Physical activity scale for the older adults: Translation, cultural adaptation, and validation of the Italian version. Curr Gerontol Geriatr Res. 2018; Article ID 8294568. https://doi. org/10.1155/2018/8294568

[35] Ismail N, Hairi F, Choo WY, Hairi NN, Peramalah D, Bulgiba A. The Physical Activity Scale for the older adults (PASE) validity and reliability among community-dwelling older adults in Malaysia. Asia Pac J Publ Health. 2015;27(8):62-72. https://doi.org/10.1177/1010539515590179

[36] Castañeda-Babarro A. Impact of COVID-19 confinement on the time and intensity of physical activity in the Spanish population. Res Sq. 2020;1-14. https://doi.org/10.21203/rs.3.rs-26074/v1

[37] López-Sánchez GF, López-Bueno R, Gil-Salmerón A, et al. Comparison of physical activity levels in Spanish adults with chronic conditions before and during COVID-19 quarantine. Eur J Publ Health. 2020;1-6. https://doi.org/10.1093/ eurpub/ckaa159

[38] Milanović Z, Pantelić S, Trajković N, Sporiš G, Kostić R, James N. Age-related decrease in physical activity and functional fitness among older adults men and women. Clin Intervent Aging. 2013;8:549-556. https://doi.org/10.2147/ CIA.S44112

[39] Hagiwara A, Ito N, Sawai K, Kazuma K. Validity and reliability of the Physical Activity Scale for the Older adults (PASE) in Japanese older adults people. Geriatr Gerontol Int. 2008;8(3):143-151. https://doi.org/10.1111/j.14470594.2008.00463.x

[40] Vaughan K, Miller WC. Validity and reliability of the Chinese translation of the Physical Activity Scale for the older adults (PASE). Disabil Rehabil. 2013;35(3):191-197. https://doi.org/10.3109/09638288.2012.690498

[41] Tel H. Disability and depression among the older adults people with chronic physical disease. Florence Nightingale J Nurs. 2014;22(2):69-75.

[42] Lopuszańska M, Szklarska A, Jankowska EA. Assessment of severity of depressive symptoms using the Polish version IA of Beck Depression Inventory in healthy men, inhabitants of Wrocław. Psychiatr Pol. 2013 Nov-Dec;47(6):1001-1009. PMID: 25007533.

[43] Zincir H, Taşçı S, Erten ZK, Başer M. The Levels of Quality of Life Depression of the Elder Living at the Rest Homes and the Factors that Affect. J Health Sci. 2008;17(3):168-174.

[44] Hollman JH, McDade EM, Petersen RC. Normative spatiotemporal gait parameters in older adults. Gait \& Posture. 2011;34(1):111-118. https://doi.org/10.1016/j.gaitpost.2011.03.024.

[45] Hollmann W, Struder HK, Tagarakis CV, King G. Physical activity and the older adults. Eur J Cardiov Prevent Rehabil. 2007;14:730-739. https://doi.org/10.1097/HJR.0b013e32828622f9 
[46] Yücel H, Kayıhan H. Effect of multipurposeful activity training at home and in the rest home on geriatric depression. Turk Jf Physiother Rehabil. 2008;19(2):74-78. https://dergipark.org.tr/tr/pub/tfrd/issue/12967/156579

[47] Lök N, Bademli K. Determination of the relationship between physical activity and depression in adult individuals. Mustafa Kemal University Journal of Social Sciences Institute. 2017;14(40):101-110.

[48] Dankel SJ, Loenneke JP, Loprinzi PD. Mild depressive symptoms among Americans in relation to physical activity, current overweight/obesity, and self-reported history of overweight/obesity. Int J BehavnMed. 2016;23(5):553-560. https://doi.org/10.1007/s12529-016-9541-3

[49] Mammen G, Faulkner G. Physical activity and the prevention of depression: a systematic review of prospective studies Am J Prevent Med. 2013;45(5):649-657. https://doi.org/10.1016/j.amepre.2013.08.001.

[50] Cengiz ŞŞ, Delen B. The investıgation of the relationship between physical activity level and the negotiation level of 65 ages and owners (example of Manisa province). Atatürk University Journal of Physical Education and Sports Sciences. 2019;21(4):25-39. https://dergipark.org.tr/tr/pub/ataunibesyo/issue/51344/612484

[51] Duray M. Examining the relationship between physical fitness, risk of falling and fear of falling in older adults people with different physical activity levels. Master of Science Thesis, Health Sciences Institute, Dokuz Eylül University, İzmir; 2013.

[52] WHO. Guidelines on physical activity and sedentary behaviour.

[53] Kesilmiș İ. The effect of the physical activity level and nutrition habits on physical and mental health. Doctoral Thesis, Educational Sciences Institute, Mersin University, Mersin; 2018.

[54] Kovalenko OG. The model of interpersonal communication in older age. Problems of modern psychology: Collected scientific papers of Kamianets-Podilsky Ivan Ohienko National University, Kostiuk Institute of Psychology of the NAPS of Ukraine;2015:191-202.

[55] Kulej-Lyko K, Majda J, Haehling Svon, et al. Could gonadal and adrenal androgen deficiencies contribute to the depressive symptoms in men with systolic heart failure? Aging Male. 2016;19(4):221-230, https://doi.org/10.1080 /13685538.2016.1208166

[56] McIntyre, RS, Mancini D, Eisfeld BS, et al. Calculated bioavailable testosterone levels and depression in middle-aged men. Psychoneuroendocrinol. 2006;31(9):1029-1035. https://doi.org/10.1016/j.psyneuen.2006.06.005

[57] Yeap BB. Hormonal changes and their impact on cognition and mental health of ageing men. Maturitas. 2014;79(2):227235. http://dx.doi.org/10.1016/j.maturitas.2014.05.015

[58] Timur S, \& Sahin NH. The prevalence of depression symptoms and influencing factors among perimenopausal and postmenopausal women. Menopause. 2010;17(3):545-551. https://doi.org/10.1097/gme.0b013e3181cf8997

[59] Vivian-Taylor J, \& Hickey M. Menopause and depression: Is there a link?. Maturitas. 2014;79(2):142-146. https:// doi.org/10.1016/j.maturitas.2014.05.014

[60] Amatriain-Fernández S, Gronwald T, Murillo-Rodríguez E, et al. Physical exercise potentials against viral diseases like COVID-19 in the older adults. Front Med. 2020;7:379. https://doi.org/10.3389/fmed.2020.00379

[61] Machado CLF, Pinto RS, Brusco CM, Cadore EL, Radaelli R. COVID-19 pandemic is an urgent time for older people to practice resistance exercise at home. Experim Gerontol. 2020;141:111101. https://doi.org/10.1016/j. exger.2020.111101 